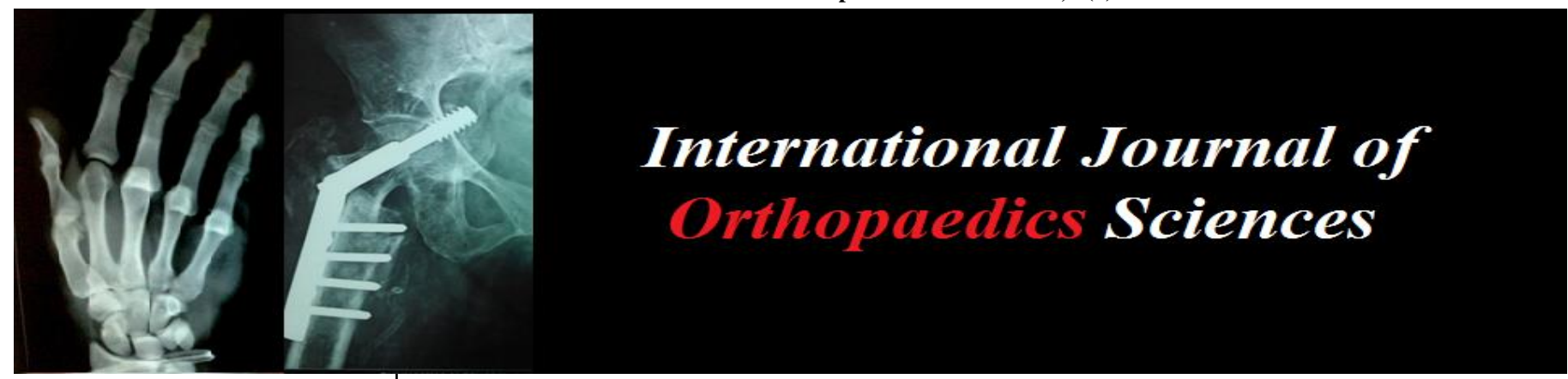

ISSN: 2395-1958

IJOS 2019; 5(2): 295-299

(C) 2019 IJOS

www.orthopaper.com

Received: 26-02-2018

Accepted: 28-03-2018

Dr Aaron D Souza

Depart. of Orthopaedics,

Yenepoya Medical College,

Mangalore, Karnataka, India

Dr. Anurag Nair

Depart. of Orthopaedics,

Yenepoya Medical College,

Mangalore, Karnataka, India

Dr. Sharath Balemane

Depart. of Orthopaedics,

Yenepoya Medical College,

Mangalore, Karnataka, India
Correspondence

Dr. Sharath Balemane

Depart. of Orthopaedics,

Yenepoya Medical College,

Mangalore, Karnataka, India

\section{A comparative study of rate of fracture union in femur neck fractures- operated within 24 hours and after 24 hours and within 7 days, effect of tamponade on rate of union in cases fixed with cannulated cancellous screws}

\author{
Dr. Aaron D Souza, Dr. Anurag Nair and Dr. Sharath Balemane
}

DOI: https://doi.org/10.22271/ortho.2019.v5.i2f.40

\begin{abstract}
Background: Osteosynthesis of femoral neck fractures is particularly indicated in patients aged under 60years. A prolonged interval between the fracture and surgical fixation has been associated with avascular necrosis (AVN) of the femoral head. The primary objective of this study was to evaluate the association between the time to surgery and the rate of union in femur neck fractures.

Methods: Patients with displaced fractures of the femoral neck (Garden III or IV) who underwent fixation with cannulated screws from August 2016 to August 2018 were evaluated retrospectively for the rate of union in femoral neck fractures.

Patients were divided into two groups according to the time to surgery (within 24 hours and within 7 days after 24 hours). Union rates were compared between the two groups.

Results: 50 patients were included in the study; the duration of follow-up ranged from 12 to 24 months. The time from fracture to surgery ranged from 24 hours to 7 days. Fourty nine patients underwent surgery within 24 hours, and fourty eight patients underwent surgery within 7 days. There were two cases of femoral head necrosis. One patient had an associated infection. There were no statistically significant differences in the overall rate of union between the groups $(\mathrm{p}=0.999)$. None of the preoperative parameters or fracture characteristics were predictive factors for union. The only factor which affects the rate of union is inadequate reduction/fixation

(odds ratio [OR]

$=35.50,95 \%$ confidence interval $[\mathrm{CI}]$

$=2.56$ to $548.36, \mathrm{p}=0.008$ ).

Conclusions: The interval between the occurrence of the injury and surgical fixation is not associated with rate of union in fractures of the femoral neck. Inadequate fracture reduction is a predictive factor in rate of union in femur neck fractures fixed with CC screws.
\end{abstract}

Keywords: Hip fracture, osteosynthesis, avascular necrosis

\section{Introduction}

In the literature, the osteosynthesis of femoral neck fractures is controversial. Recent studies have demonstrated the superiority of hip arthroplasty compared with internal fixation in patients aged over 65 years ${ }^{[1,2]}$. However, internal fixation is the method of choice for patients aged under 60 years, and for undisplaced fractures ${ }^{[3]}$. Different studies have demonstrated high complication rates for osteosynthesis; these complications primarily include avascular necrosis $(\mathrm{AVN})$ of the femoral head and non-union ${ }^{[1,4]}$. The interval between the fracture and surgical fixation has been implicated as a risk factor for the development of AVN ${ }^{[5]}$. The 12hour period after fracture is generally considered to be the boundary between early and late fixation ${ }^{[3,4]}$; however, this In a recent meta-analysis, Damany et al. did not confirm this association ${ }^{[3]}$. There are a few studies on late fixation (more than 7 days after fracture) in the literature, but there is no evidence of its role in the development of complications. Among other factors associated with the prognosis for fractures of the femoral neck, the initial deviation and quality of postoperative reduction appears to be important. 


\section{Materials and Methods}

This is a retrospective study carried out in tertiary health care between August 2016 to August 2018, the charts of all patients with displaced fractures of the femoral neck (Garden III or IV) who underwent fixation with three cannulated screws in the inverted triangle configuration from August 2016 to August 2018 were evaluated retrospectively for the development of orthopaedic complications.

Patients were divided into two groups according to the time to surgery (within 24 hours or more than 24 hours but within 7 days. Union rates were compared between the two groups. Regression analyses were performed to assess the risk factors for complications.

Two surgeons from the Trauma Group performed the operations. A standardised technique was used: three cannulated screws $(7.3 \mathrm{~mm})$ were set in the configuration of an inverted triangle with two upper screws and one lower screw. The intraoperative and postoperative data included the operative time, length of hospital stay after surgery, fracture reduction by the Garden index in the immediate postoperative period, and presence of complications. To compare the union rates, the patients were divided into two groups according to the time to surgery. The primary endpoint of the study was to compare the complication rates between the two groups. The secondary endpoints included investigating the association between time to surgery and union rate by regression analysis, and evaluating the association between union rate and patient demo- graphics, degree of osteoporosis, fracture classification and quality of postoperative reduction.

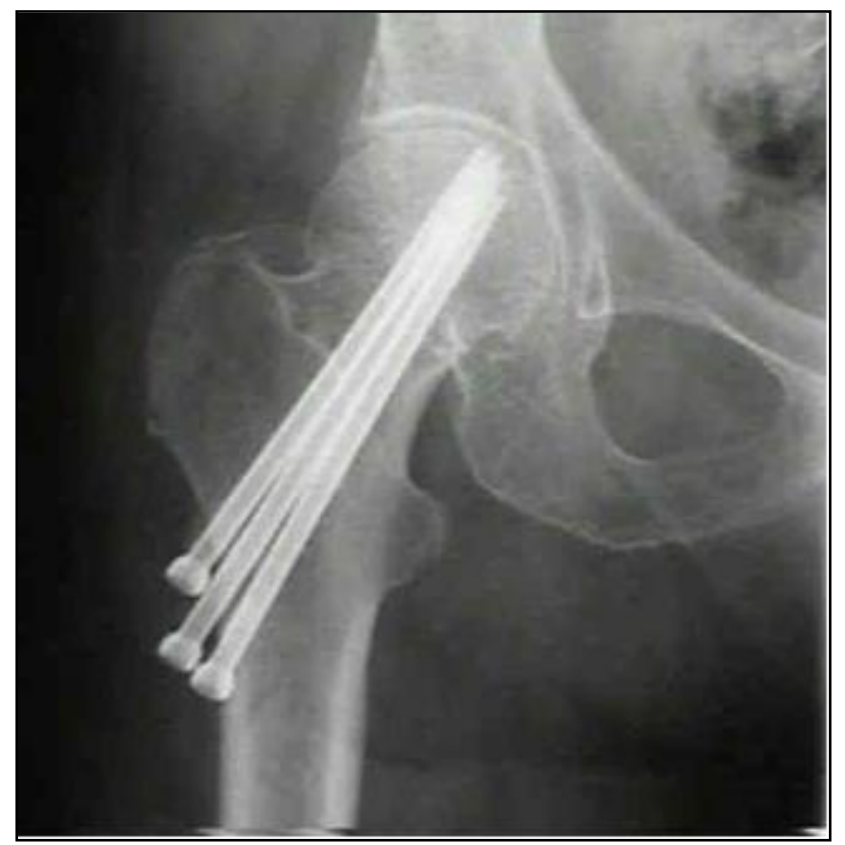

Fig 1: Post op x-ray CC screw fixation for fracture neck of femur

Follow up Post operatively, the patients were advised to ambulate strictly with non-weight bearing crutches until there was radiological evidence of union. Post-operative hip radiographs were taken and these were subsequently analysed for acceptability of fracture reduction and fixation using the Garden's Alignment Index. These patients were then followed up till there was evidence of radiological union. Documented incidence of non-union and avascular necrosis were noted and analysed individually in relation to the following risk factors: Age of patient, elapsed time between injury and surgery, presence of posterior comminution, fracture displacement at presentation. number of cannulated screws used, fracture reduction acceptability, anatomical location of fractures.

\section{Results}

50 patients were included in the study; the duration of followup ranged from 12 to 24 months. The time from fracture to surgery ranged from 3 to 15 days. Twenty-five patients underwent surgery within 24 hours, and 25 patients underwent surgery after 24 hours and within 7 days. There were two cases of femoral head necrosis. One patient had an associated infection; one patient experienced non-union, and another demonstrated osteosynthesis failure. There were no statistically significant differences in the overall rate of complications between the groups $(p=0.999)$. None of the preoperative parameters or fracture characteristics were predictive factors for complications. The only factor associated with the development of complications was inadequate fracture reduction in the anteroposterior (AP) view (odds ratio $[\mathrm{OR}]=35.50,95 \%$ confidence interval $[\mathrm{CI}]=2.56$ to $548.36, \mathrm{p}=0.008)$.

The presence of comorbidities was considered to be a potential confounding factor that could be associated simultaneously with time to surgery and the occurrence of complications.

Regression analysis was performed to study this association. The sample size was defined by the number of patients who underwent the operation in the given period.

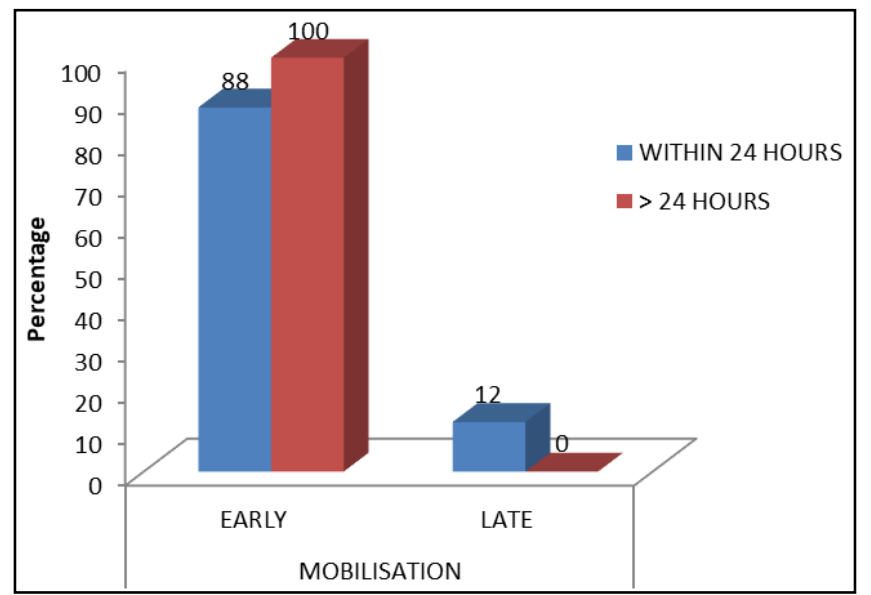

Fig 2: Comparison between two groups in view of mobilisation (Post op)

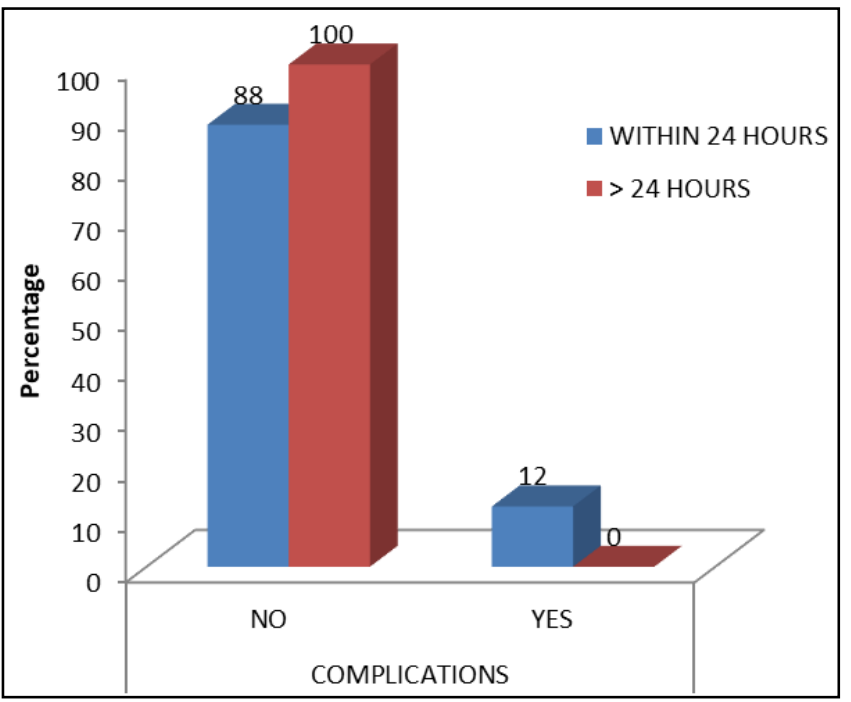

Fig 3: Comparison between two groups in view of complications 


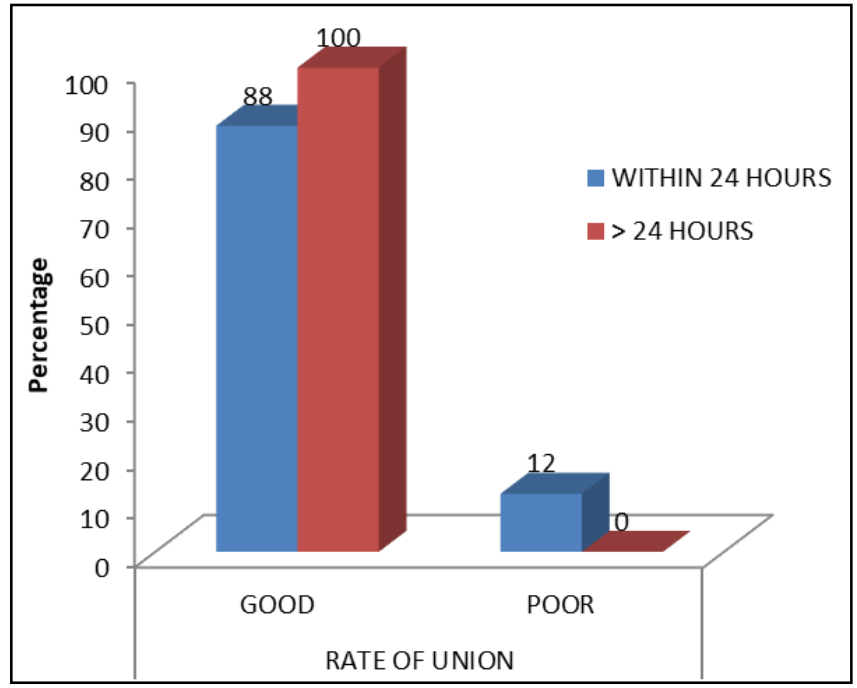

Fig 4: Comparison between two groups in view of rate of union

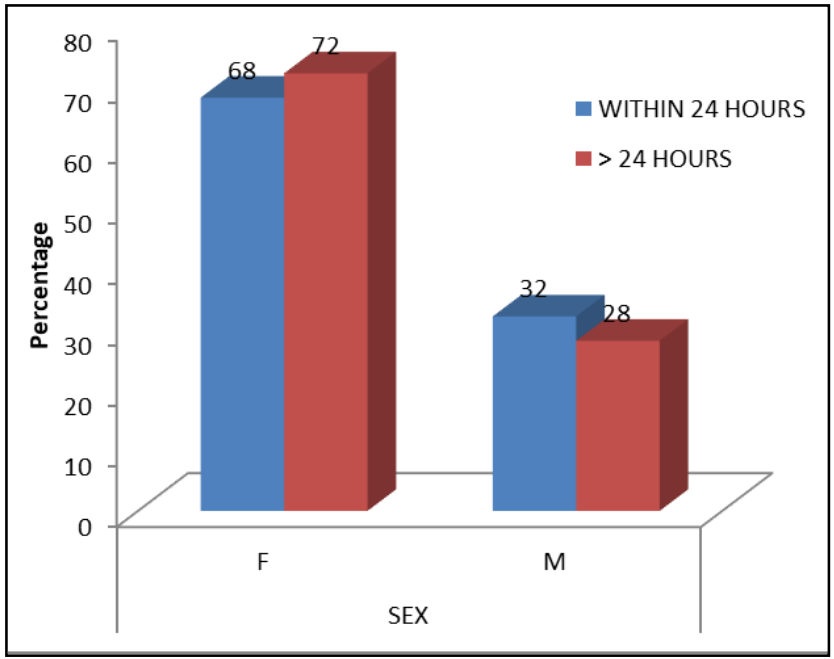

Fig 5: Gender comparison between two groups with fracture neck of femur

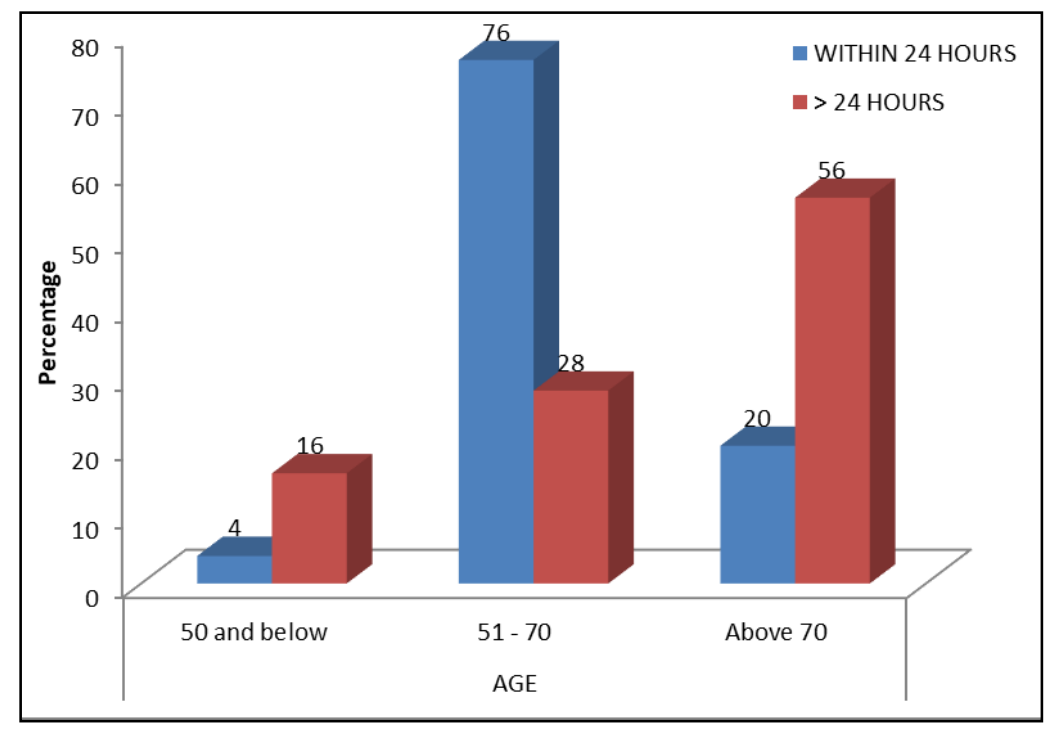

Fig 6: Age comparison between two groups with fracture neck femur

Table 1: Summary of Comparison of Age, Sex, Rate of union and mobilisation between two groups

\begin{tabular}{|c|c|c|c|c|c|c|c|}
\hline & & \multicolumn{6}{|c|}{ OPERATED } \\
\hline & & \multicolumn{2}{|c|}{ WITHIN 24 HOURS } & \multicolumn{2}{|c|}{$>24$ HOURS } & \multicolumn{2}{|c|}{ Fishers exact test } \\
\hline & & Count & Column N \% & Count & Column N \% & p value & \\
\hline \multirow{4}{*}{ AGE } & 50 and below & 1 & $4.0 \%$ & 4 & $16.0 \%$ & \multirow{4}{*}{.003} & \multirow{4}{*}{ HS } \\
\hline & $51-70$ & 19 & $76.0 \%$ & 7 & $28.0 \%$ & & \\
\hline & Above 70 & 5 & $20.0 \%$ & 14 & $56.0 \%$ & & \\
\hline & Total & 25 & $100.0 \%$ & 25 & $100.0 \%$ & & \\
\hline \multirow{3}{*}{ SEX } & $\mathrm{F}$ & 17 & $68.0 \%$ & 18 & $72.0 \%$ & \multirow{3}{*}{.758} & \multirow{3}{*}{ NS } \\
\hline & $\mathrm{M}$ & 8 & $32.0 \%$ & 7 & $28.0 \%$ & & \\
\hline & Total & 25 & $100.0 \%$ & 25 & $100.0 \%$ & & \\
\hline \multirow{3}{*}{ RATE OF UNION } & GOOD & 22 & $88.0 \%$ & 25 & $100.0 \%$ & \multirow{3}{*}{.235} & \multirow{3}{*}{ NS } \\
\hline & POOR & 3 & $12.0 \%$ & 0 & $.0 \%$ & & \\
\hline & Total & 25 & $100.0 \%$ & 25 & $100.0 \%$ & & \\
\hline MOBILISATION & EARLY & 22 & $88.0 \%$ & 25 & $100.0 \%$ & .235 & $\mathrm{NS}$ \\
\hline
\end{tabular}

\section{Discussion}

Fractures of femoral neck remain a challenge in the clinical practice of orthopaedic surgeons. It is still a subject of debates over the years with regards its management. Generally, the accepted mode of treatment is internal fixation either by open or closed reduction in younger patients and patients without degenerative changes in the hip joint. Total hip replacement is generally a preferred option for patients with pre-existing degenerative changes in the hip. The primary aim of internal fixation in these fractures is to achieve anatomical reduction in order to restore or preserve the precarious blood supply to the head of femur, more so in the younger age group and prevention of future complications such as avascular necrosis and non-union. Stable anatomical reduction can be achieved by means of three standard cannulated screws $(7.3 \mathrm{~mm}$ cancellous) inserted according to the " 3 Point Principle".

The overall incidence of avascular necrosis in our series was $16.98 \%$, which is comparable with the majority of previous published data (ranging from 10\% - 30\%) ${ }^{[1,2,3,4]}$. Avascular necrosis of the head of femur leads to segmental collapse of 
the head which predispose to secondary hip joint degenerative changes, necessitating subsequent revision or joint replacement surgery.

Previous studies have shown contradicting findings with regards the relationship between age of patient to subsequent incidence of avascular necrosis. The traditional belief is that there is decreasing risk of avascular necrosis with increasing age, as shown by Graham ${ }^{[8]}$, Barnes ${ }^{[9]}$ and Luizou ${ }^{[10]}$. However, Shih \& Wang [11], concluded that there was no significant association between age of patient and the incidence of avascular necrosis developing later on in life. Our findings seem to correlate with the conclusion of Shih \& Wang as there was no significant association between age and incidence of avascular necrosis.

Urgent reduction and stable fixation of femoral neck fracture less than six hours after injury has been shown to reduce the risk of avascular necrosis ${ }^{[12]}$. Jain reported that time to reduction of the fracture was found to be the only significant contributing factor, though others have shown no difference between early or later surgery ${ }^{[13]}$.

In our study, we found no cases of AVN when the fracture was reduced and fixed within six hours but the incidence increased with increasing time interval. However this is not statistically significant due to the small number of cases.

Therefore, there is still a case for urgency in getting these patients to surgery and stabilising these fractures.

One of the most important issues during closed reduction and percutaneous cannulated screw fixation is the adequacy of fracture reduction and subsequent stable fixation.

Adequate fracture reduction is assessed using the Garden Alignment Index. This index refers to the angle of the compression trabeculae on AP view relative to the longitudinal axis of the femoral shaft and the angle of the compression trabeculae on the lateral view relative to the femoral shaft.

In a normal radiograph of the hip joint, this angle should be $160^{\circ}$ on the AP view, while on the lateral view it is $180^{\circ}$. Acceptable reduction is defined as a reduction angle lying within $155^{\circ}-180^{\circ}$ range on both views. It is universally accepted that risk of avascular necrosis increases substantially if the alignment index falls out of this acceptable range, especially if there is a valgus reduction of more than 20 degrees As this is a retrospective study documenting a twoyear experience in the treatment of intracapsular neck of femur fracture by closed reduction cannulated screw fixation, the follow up period for the patients was not standardised.

Therefore the incidence of avascular necrosis could have been underestimated. Secondly, the number subjects are relatively small, compared to other studies and this could have affected the conclusions. Lastly, some cases of early avascular necrosis of the head of femur might not have been picked up as Magnetic Resonance Imaging was not used for these cases.

\section{Conclusion}

In our two years' experience in treating neck of femur fracture with closed reduction and cannulated screw fixation, we found no significant relationship between the incidence of avascular necrosis in relation to age of patient, fracture displacement, number of cannulated screw used, fracture reduction acceptability and anatomical locations of fracture. The time interval from injury to surgery and the presence of posterior comminution did influence the rate of avascular necrosis but due to the small numbers in the study, it is not statistically significant. In conclusion, cannulated screw fixation remains a viable option of treatment for neck of femur fracture regardless of operated within 24 hours or after 24 hours but within 7 days.

\section{References}

1. Pare A. The work of that famous chirurgion A. Pare. Translated out of Latin and compared with French by Tho. Johnson, book XV London, T. Cotes and R. Young, 1634.

2. Dickson JA. The unsolved fracture. J Bone Joint Surg. 1953; 35:805-22.

3. Garden RS. Low-angle fixation in fractures of the femoral neck. J Bone Joint Surg. 1961; 43(4):647- 63.

4. Garden RS. Malreduction and avascular necrosis in subcapital fractures of the femur. J Bone Joint Surg. 1971; 53(2):183-97.

5. Garden RS. Reduction and fixation of subcapital fractures of the femur. Orthop Clin North Am. 1974; 5:683-712.

6. Mcelvenny RT. The importance of the lateral x-ray film in treating intracapsular fracture of the femur. Am J Orthop. 1962, 212-5.

7. Harris WH. Traumatic arthritis of the hip after dislocation and acetabular fractures: treatment by mold arthroplasty an end-result study using a new method of result evaluation. J Bone and Joint Surg.

8. Graham J. Early or delayed weight-bearing after internal fixation of transcervical fracture of the femur. A clinical trial. J Bone Joint Surg Br. 1968; 50:562-569. [PubMed] [Google Scholar]

9. Barnes R, Brown JT, Garden RS, Nicoll EA. Subcapital fractures of the femur. A prospective review. J Bone Joint Surg Br. 1976; 58:2-24. [PubMed] [Google Scholar]

10. Loizou CL, Parker MJ. Avascular necrosis after internal fixation of intracapsular hip fractures; a study of the outcome for 1023 patients Injury. Int. J Care Injured. 2009; 40:1143-1146. [Pub Med] [Google Scholar]

11. Shih $\mathrm{CH}$, Wang KC. Femoral neck fractures. 121 cases treated by Knowles pinning. Clin Orthop Relat Res. 1991; 271:195-200. [PubMed] [Google Scholar]

12. Jain R, Koo M, Kreder HJ. Comparison of early \& delayed fixation of subcapital hip fractures in patients sixty years of age or less. J Bone Joint Surg. 2002; 84:1605-1612. [PubMed] [Google Scholar]

13. Manninger J, Kazar G, Fekete G. Significance of urgent (within $6 \mathrm{hrs}$ ) internal fixation in the management of fractures of the neck of the femur. Injury. 1989; 2:101105. [PubMed] [Google Scholar]

14. Trueta J, Harrison MHM. The normal vascular anatomy of the femoral head in adult man. Bone Joint Surg Br. 1953; 35:442-461. [PubMed] [Google Scholar]

15. Sevitt S, Thompson G. The distribution and anastomoses of arteries supplying the head and neck of the femur. J Bone Joint Surg Br. 1965; 47:560-573. [PubMed] [Google Scholar]

16. Huang TW, Hsu WH, Peng KT. Effect of integrity of the posterior cortex in displaced femoral neck fractures on outcome after surgical fixation in young adults. Injury, Int. J Care Injured. 2011; 42:217-222. [PubMed] [Google Scholar]

17. Frangakis EK. Intracapsular fractures of the neck of the femur. Factors influencing non-union and ischaemic necrosis. J Bone Joint Surg Br. 1966; 48:1730. [PubMed] [Google Scholar]

18. Scheck M. Intracapsular fractures of the femoral neck. Comminution of the posterior neck cortex as a cause of 
unstable fixation. J Bone Joint Surg Am. 1959; 41:11871200. [PubMed] [Google Scholar]

19. Scheck M. The significance of posterior comminution in femoral neck fractures. Clin Orthop Relat Res. 1980; 152:138-142. [PubMed] [Google Scholar]

20. Alho A, Benterud JG, Muller C, Husby T. Prediction of fixation failure in femoral neck fractures. Comminution and avascularity studied in 40 patients. Acta Orthop Scand. 1993; 64:408-410. [PubMed] [Google Scholar 